International Journal of Child, Youth, and Family Studies (2014): 5(4.1) 629-648

\title{
PHOTO INTERVIEWS WITH CHILDREN: RELATING THE VISUAL AND THE VERBAL FROM A PARTICIPATION PERSPECTIVE
}

\section{Ulrike Zartler}

\begin{abstract}
The integration of visual prompts into qualitative interviews is regarded as a useful tool in attempting to give children the possibility of verbalizing memories and describing abstract issues. Furthermore, photo interviews are supposed to promote children's participatory research experiences. Less attention has been paid to how visual and verbal elements may be interrelated throughout the research process. Drawing on data from an Austrian empirical study with 50 children aged 10 years, the objective of this paper is to describe the combination of visual and verbal data in detail. Special emphasis is put on identifying factors that influence children's participation. The potential and limitations of photo interviews as a participative method of conducting research with children are elaborated. Although this approach does not per se decrease power differentials, enhance participation, or respect children's agency, it has a high potential to facilitate such action, if applied carefully, critically, and conscientiously.
\end{abstract}

Keywords: children, photo interviews, qualitative interviews, participation, agency

Ulrike Zartler, Ph.D. is an Assistant Professor of Family Sociology at the University of Vienna, Department of Sociology, Rooseveltplatz 2, A-1090 Vienna, Austria. E-mail: ulrike.zartler@univie.ac.at 
Research with children is often based on qualitative interviews. Integrating visual prompts into these interviews is regarded as a useful tool, as photo interviews yield considerable advantages. They support children in verbalizing memories and describing abstract issues, are able to increase children's engagement with scientific studies, contribute to a pleasant atmosphere, and are assumed to support participative elements in research with children (Cappello, 2005; Clark-Ibáñez, 2004; Cook \& Hess, 2007; Croghan, Griffin, Hunter, \& Phoenix, 2008; Eldén, 2012; Thomson, 2008). However, less attention has been placed on the question of how to relate the visual and the verbal throughout the research process. Drawing on data from an Austrian empirical study ${ }^{1}$ with 50 10-year-old children, I explore the potential of this method and describe how photos can be used in combination with an open, storytelling interview method. The aims of this paper are twofold: (a) to provide a detailed description of the ways in which visual and verbal elements were related in a photo interview study, and (b) to explore whether and how a thorough combination and consideration of both parts throughout the research process can contribute to participatory aspects.

\section{Photo Interviews in Research with Children}

Research with children is often based on qualitative interviews, which are regarded as an adequate tool to gain direct access to children's perspectives (Christensen \& James, 2008; Fraser, Lewis, Kellett, \& Robinson, 2004; Greig, Taylor, \& MacKay, 2007; Qvortrup, Corsaro, \& Honig, 2009). Yet interviews also have disadvantages: It may be challenging for children to verbalize memories or to find the right words to describe abstract processes and circumstances vis-à-vis an adult researcher; children may tire quickly during interviews; and it may prove difficult to keep their interest for a longer period of time (Cappello, 2005; Fuhs, 2000; Heinzel, 2000).

One way of overcoming these difficulties is to give children the possibility of visualization. Over the past few years, it has become increasingly popular in qualitative childhood research to combine verbal and visual data. The method of incorporating a photograph into a research interview has been termed photo-elicitation interview (Clark-Ibáñez, 2004; Harper, 2002), participatory photo interview (Jorgenson \& Sullivan, 2009; Kolb, 2008), autophotography (Worth \& Adair, 1972; Ziller, 1990), autodriven interview (Clark, 1999), or photovoice (Wang \& Burris, 1997; Wang, Ling, \& Ling, 1996).

While it is common to use photographer- or researcher-produced visual prompts for interviews with adults (Harper, 2001; Schwartz, 1989, 1992), it is especially recommended to use participant-produced pictures in research with children, and thereby invite children themselves to give insights into different spheres of their lives (Cappello, 2005; Clark-Ibáñez, 2004; Cook \& Hess, 2007; Croghan et al., 2008; Eldén, 2012; Harper, 2002; Thomson, 2008). Photographs or drawings are

\footnotetext{
${ }^{1}$ The research team consisted of the author who was one of the project leaders, two other researchers (Andrea Marhali, Johannes Starkbaum), and the second project leader Rudolf Richter. The study was funded by the Austrian Federal Ministry of Economy, Family and Youth.
} 
applied for this purpose, the latter appearing to be particularly adequate for younger children (Backett-Milburn \& McKie, 1999; Punch, 2002a).

The possibilities of combining visual and verbal elements in photo interviews with children cover a wide spectrum. A reduced number of pictures may be employed as a teaser that helps the respondents start to talk, while all produced photos may be used during the interview with the aim to talk in detail about each picture. Photos may be pre-selected by the researcher - in combination with specifically prepared questions regarding each picture - or alternately be selected by the respondent. Furthermore, different importance is assigned to the different elements: While some researchers regard it as crucial to discuss participant-produced pictures with the children who created the photos (White, Bushin, Carpena-Méndez, \& Ní Laoire, 2010), others ask children to write short comments on each photo explaining why they took it and what they intended the picture to say (Darbyshire, MacDougall, \& Schiller, 2005).

The principal benefits said to be associated with photo interviews in research with children can be summarized as follows:

1. Relating to pictures during the interview is intended to enrich the process of reflection and to support children in verbalizing their thoughts. Images are assumed to evoke other and deeper elements of human consciousness than do words, and therefore to enhance the process of remembering (Clark-Ibáñez, 2004; Harper, 2002). The use of photographs allows respondents to reflect on associations they would not see as related without a visual template. Thus, the images may trigger a relating to content that otherwise may remain poorly understood, overlooked, or even concealed from the researcher (Collier, 1967; Mannay, 2010; Schwartz, 1989). Recently, photo interviews have also been shown to be fruitful in the exploration of particularly challenging research issues, such as the perspectives of young refugees (McBrien \& Day, 2012) or sensitive aspects of children's family lives (Zartler \& Richter, 2014).

2. The use of photos and the process of taking them are supposed to be amusing for children (Cook \& Hess, 2007). Thus, photo interviews are regarded as a method that may increase children's interest in participating in a study, intensify their engagement with a scientific research project, and maintain their interest throughout the research process (Cappello, 2005; Clark-Ibáñez, 2007; Croghan et al., 2008; Einarsdóttir, 2005; Harper, 2002; Newman, Woodcock, \& Dunham, 2006; White et al., 2010).

3. The incorporation of photos into research interviews with children is argued to contribute to a pleasant atmosphere for interviews. Talking about a visual prompt may also ease the strangeness of being interviewed by an adult, as this provides a common focus for the interviewer and the respondent (Clark-Ibáñez, 2004; Cook \& Hess, 2007; Wuggenig, 1990).

4. The use of participant-produced photographs is particularly assumed to support participative elements in research with children, to enhance research that regards children as active and competent participants, and therefore to decrease power differentials between interviewers and respondents (Cappello, 2005; Packard, 2008; Pink, 2013). When children take photos themselves, they are in the role of active experts who can explain their self-produced photographs to the researcher(s) (Cook \& 
Hess, 2007; Hill, 1997). Respondents have a clear, tangible prompt in preparing for the interview, which gives them the opportunity to reflect on the research topic beforehand. This may balance previous background knowledge of the researcher and the researched. Moreover, photo interviews are often particularly regarded as considering, or even promoting, children's competency and agency. These are essential topics in research with children (Eder \& Fingerson, 2001; Lange \& Mierendorff, 2009; Valentine, 2011), as they are increasingly regarded as persons who actively shape their own lives and their social surroundings (James, 2009; James, Jenks, \& Prout, 1998; Kuczynski, 2003; Morrow, 2003; Shehan, 1999).

In accordance with this perspective, a debate on children's participation in social science research has emerged, and a considerable body of literature has been produced with regard to the need for a critical examination of the ways in which children's participation is theorized and practiced in the social sciences (Christensen \& James, 2008; Gallacher \& Gallagher, 2008; Hill, Davis, Prout, \& Tisdall, 2004; Holland, Renold, Ross, \& Hillman, 2010; James, 2007; Powell \& Smith, 2009; Thomas \& O'Kane, 1998). In the framework of this discussion, it has been shown that research using participatory elements is also often and largely managed by researchers and does not necessarily "empower” children (Gallacher \& Gallagher, 2008; Holland et al., 2010; Punch, 2002b; Thomson, 2007).

In particular, a need to conceptualize participation as a dialogic encounter has been expressed, promoting a shift from listening to children to establishing dialogues in research (Cooper, Nazzari, Kon Kam King, \& Pettigrew, 2013; Graham \& Fitzgerald, 2010; Neale, 2002), while considering children's views on participative research methods (Hill, 2006; Warming, 2011). Furthermore, research phases that are especially challenging with regard to children's participation have been identified. One such example is the recruiting process, as researchers' access to children is usually tightly controlled, and children mostly cannot be approached directly (Alderson, 2005; Sinclair, 2004). As a consequence, particular groups of children are already excluded from research before fieldwork has even been initiated. Scholarly work on the potential exclusion of particular (groups of) children has thus been on the increase (Powell \& Smith, 2009; Roberts, 2008).

Although photo interviews provide considerable advantages and are widely used in research with children, less attention has been paid to the question of how visual and verbal elements may be related throughout the research process. Responding to this challenge, the aim of this paper is twofold: first, as based on an Austrian study, to describe in detail the ways in which visual and verbal elements can be exactly related; and second, to explore whether and how a combination and consideration of visual and verbal elements may contribute to children's participation in social science research.

\section{Data and Methods}

The present study is empirically based on photo interviews with 50 Austrian children aged 10 years. The study aimed to explore various aspects of family life and included such topics as family activities, organisation and challenges of everyday family life (e.g., family time, children's participation in family decisions), relationships between family members, and attitudes towards different family forms. 
This stands in relation to scholarly work analyzing children's lives and relationships within their families (Morrow, 1998; Rigg \& Pryor, 2007; Smart, 2006).

The children took photos within their families and during leisure time. These photos then provided the basis for the interviews. Additionally, interviews based on topic guides were carried out with the children's parents, and at least one parent was interviewed for every child (71 parents in total; these data are not considered for this paper). The parents did not see the photos that their children produced in the framework of this study. If parents asked questions about the photos or speculated about contents, the interviewers referred to confidentiality.

The recruitment of participants was based on initial contacts with children in a classroom setting. Twenty boys and 30 girls were interviewed. The participating children had various background characteristics in relation to family forms, social background, migration status, and parental working conditions. The respondents were interviewed at school, as we were allowed to conduct the interviews during school hours and to use schoolrooms the respondents were familiar with. The interview duration was between 30 minutes and one hour.

We used an interview type that brings together photo interviews and semistructured interviews based on topic guides. The children were asked to take pictures with a disposable camera according to a specific schedule, covering the following categories:

1. Who is part of my family?

2. What I like about my family.

3. What I don't like about my family.

4. How we spend our time during the week.

5. How we spend our time on weekends.

These categories were formulated by the research team and were based on our experiences during the pretest. The categories were considered to cover a broad range of topics with regard to children's families, while giving the participating children the allowance to choose the subjects of their photos relatively autonomously. The participating children received an instruction sheet with information on how to handle the camera, the number of 27 photos per camera, and the categories to take pictures of. The respondents were requested to produce at least one picture per category. We provided the children with a timetable and smiley-face stickers that were used to mark completed categories on their instruction sheets. Our intention in using photographs was not, as Clark-Ibáñez (2004) mentions, to give the children the opportunity to "present the very best parts of their lives" (p. 1508), but rather to establish a broad, kaleidoscopic insight into their family lives (Holland, 1997; Mason \& Tipper, 2008).

In sum, the study comprises 1,030 photos, 992 of them being useable (see below). Their manifest content was analysed and described, including also children's comments. All interviews were recorded and transcribed verbatim. Data analysis was based on the transcripts of all interviews, combining a grounded theory approach and content analysis (Froschauer \& Lueger, 2003; Strauss \& Corbin, 1990; see also Zartler, 2010, 2014). 


\section{Combination of the Visual and the Verbal in Photo Interviews with Children}

The following section explores how the combination of visual and verbal parts in photo interviews with children - along with participatory aspects of this research method - can be pursued throughout the research process. Its aim is to present in detail how the research was conducted in this respect.

\section{Preparing for interviews}

One indispensable precondition for the combination of visual and verbal elements in research with children is to ensure wide access to the generation of the visual parts, and to create conditions for all children to participate. While interviews are usually open to all participants who are able to express their thoughts verbally, access may be limited for methods requiring technology, such as photo elicitation on the basis of participant-produced photos. In the study at hand, it was essential to consider in detail how the interviews should take place and to provide enough time for detailed pre-interview considerations within the research team. One main concern was to avoid excluding particular children in choosing participant-produced photos as an approach. Factors that need to be taken into account in this regard are the availability of technical equipment, children's technical competencies and visual literacy, as well as adequate ways of recruiting respondents.

In terms of available technical equipment, the use of mobile phones for photoshooting was considered as one option when designing the study. In the course of predata collection conversations with children, teachers, and parents in several schools, it became apparent that some ten-year-old children would possibly be excluded; for example, those with technology-averse parents or those with a disadvantaged socioeconomic background who do not have camera-equipped devices of their own. Researchers are thus called to explore ways to provide children with technical equipment in order to give them a chance to participate in such settings.

Another essential consideration addresses children's technical competencies and knowledge, which may vary within a group of ten-year-olds. The type of camera to use is an important decision in photo interview projects with children. Disposable cameras are practical, as they require little technical experience and training, are easy to handle, and are available at low cost. As disposable cameras are designed for adults, some models are too complicated for use by children, do not fit well with their anatomy, and require too much physical strength or distinctive fine motor skills.

We checked different types of cameras in a pre-test with children and selected the preferable model. During initial contacts at school (see below), we showed this camera to the children, let them try to take pictures, and provided them with detailed information on their photo-shooting task (e.g., categories to be portrayed, limited number of photos on the film, use of the flash). It was of particular importance to remind the children that the use of analogue cameras made it impossible to take an unlimited number of photos or to delete photos once they were made. All participating children had the opportunity to test and practice the camera handling together with the research team. Seven to 10 days after distribution, the research team collected the cameras. The photos were developed, and each child's set of photos was kept in a separate envelope. The analysis was prepared by numbering every single picture with 
the child's code and a consecutive number for every single photo. This was important in order to avoid confusion between different respondents' pictures during the analysis.

In sum, the 50 interviewed children produced 1,030 photos. The photo-taking action was very successful in terms of useable pictures, which may be related to the children's ability to test the cameras beforehand under the researchers' guidance, as described above. Only 38 photos (4\% of all pictures) were not useable, mainly due to missing flash or unintended pressing of the release. Nearly 1,000 photos displayed recognizable motives and were finally used for analysis. On average, every participating child produced 21 photos.

Another matter affecting possibilities of participation is children's visual literacy and expressive ability. Commenting on a photo requires the ability to describe the picture and to verbalize one's related thoughts. From a developmental point of view, 10-year-old children are supposed to have acquired these abilities (Birney \& Sternberg, 2011; Denham et al., 2011; Piaget, 1972). Furthermore, at the age of 10, children in the Austrian educational system have spent four years together with their classmates and are thus in a familiar surrounding. Therefore, it was supposed that both children's abilities and the educational framework would render the classroom setting with 10-year-old respondents particularly suitable. Nevertheless, combined with the strangeness of talking to an adult researcher, it may intimidate children to perform the described tasks during an interview situation. Thus photo elicitation though not an exclusively verbally oriented method - favours children who master verbal expression well, and may exclude children who have problems in adequately applying speech for communication (Morris, 2003; Rabiee, Sloper, \& Beresford, 2005). These factors are difficult for the research team to influence, but can be eased by attempting to create a comfortable atmosphere (Eder \& Fingerson, 2001; Lewis, 2009; Ribbens McCarthy, Holland, \& Gillies, 2003).

The ways of contacting and recruiting children for a photo interview study are also related to their possibilities of participation. We preferred to approach the children directly instead of via their parents. In accordance with legal and ethical requirements, parents as well as school authorities were first briefly informed about the contents of the study and gave their permission to contact children at school. The respondents were approached in a classroom setting (for a detailed description, see Zartler, 2010) where the research team presented the planned study. We informed the children about the research contents and their task of taking pictures according to a specific schedule. The children were encouraged to ask questions regarding the study and to share their thoughts about participating in the research. Children were in turn requested to pass on an information sheet to their parents, which contained details of the study, contact dates, and a permission slip to sign if they agreed to participate. The children thus invited their parents to take part in the study. This worked out well, as the children were enthusiastic about participating in a research project and producing photos for this purpose (Zartler, 2010). While Lewis (2009) stated that children would prefer to be approached by a parent rather than a stranger, our experience was that children appreciated being contacted directly. The research team was in contact with the children several times before the interview took place: when presenting the study, when distributing the cameras, and when collecting the cameras. This was advantageous, as the children became familiar with the research team. 
Summing up these experiences in preparing photo interviews with children, it is particularly important to provide carefully pre-tested, child-friendly technical equipment and comprehensible instructions for handling the cameras, as well as to create an adequate interview atmosphere. Otherwise, a child's ability to participate in such a research project is limited.

\section{Carrying out interviews}

In the study at hand, the interviews were structured by the respondents according to the photos, with the researchers always bearing in mind the topic guide covering the principal themes of the study (see above). After children had allocated the photos to the different categories, we let the photos thematically guide the interview. Interviewers did not ask questions, but left it up to the respondents to determine the issues and the level of detail. As the topic guide and the instruction sheets for taking photos were structured similarly, it was relatively easy to consider all main topics during the interviews. If children elaborated in detail on specific aspects, their narrations were always prioritized against an attempt to collect elaborations of similar length on every topic. From our experience, encouraging children to engage in a narrative conversation went together well with the more constrained categorizing of photos, as most children liked the categorization part during the interview.

All remaining questions were asked in the last part of the interview once the children had completed their accounts. This method combines narration-based interviews with topical interviews. It gives children a scope and offers them the opportunity to put a focus, to talk about their own agendas, to choose narrations independently, and to consider their own relevance systems (Flick, 2014; Lamnek, 1995).

The interviews were conducted approximately one week after the children had finished the photo-taking phase. When starting the interview, we first asked every child about his or her experiences with taking the pictures. In general, the participating children answered that they liked the photo-taking phase and were very engaged in this task. They took their job seriously and often found it difficult to choose the subject of their photos and to decide about the next picture to be taken in order to complete the instruction sheet. Most children reported that they felt important when handling the camera and contributing to a scientific study. Some of them complained that the given time for producing the photos was too short, but in general the interviewed children did not report any problems in understanding the instructions and performing their photo-shooting tasks.

From the interviews with parents, we could reconstruct that parents knew about the photo-taking schedule and that some parents reminded their children to take photos in order to finish their photo-shooting task. However, no evidence for a parental influence on the photographed topics could be found. Neither children nor parents in their interviews mentioned resistance that photos were taken at home and in private situations. However, a selective effect was evident, as parents who had reservations about the photo-taking action did not give their consent to participate in the study. 
We handed the photos over to the child, referring to matters of confidentiality and emphasizing that the parents would not see the pictures during their interviews. At the time of the interview, the researchers had not looked at the pictures, but had seen only the reverse side of the photos when numbering them (see above). This was considered important in order to avoid researchers' advantage in knowledge and to attribute the power of selection to the children. Respondents were told that the research team kept digital copies for the analysis. The photos were regarded as creative materials that belonged to the children personally and were only to be used by the research team for scientific reasons.

The children were then asked to allocate the photos to the five categories listed on the instruction sheet. It was clearly explained to the children that the researchers did not regard any photo as unfitting or inappropriate. All taken photos, also the few blurred ones, provided the basis for selection, and children could freely decide on the specific photos they wanted to comment on. The children could choose to use only a selection of photos for narrations, which they usually did. The respondents were also free to comment on the pictures, their significance, and the reasons for creating them in a narrative way during the interview, thus producing detailed conversations with some children about their thoughts when taking the photos. Most respondents liked the allocation task and categorized the photos rather quickly, often within several minutes.

Several challenges were connected with this interview phase. At times, children had difficulties remembering the category for which a particular photo had been produced; some respondents allocated one photo twice because they wanted a picture to be present in more than one category. This was accepted, but the interviewer tried to reconstruct whether children elaborated on a preferred categorization during the interview. It is important to notice that, in children's narrations, photos were not exclusively used in connection to the category they had been allocated to. The pictures often rather had the function of a trigger that initiated narrations on other topics than those that were manifestly displayed (see Zartler \& Richter, 2014).

After the allocation task, the children usually explained some photos in detail, whereas other pictures were grouped together and commented on in an overview style. Most respondents started by using portraits of their family members and friends in order to make their social embedment explicit to the interviewer, and then elaborated on the photos representing activities in their spare time and on weekends. The children could choose the topics they wanted to elaborate on and determine the levels of detail. The interviewers listened carefully and encouraged the children to speak freely and to comment on the photos in an open and storytelling way. From time to time, the respondents were asked to refer to the number on the back of their photos, a piece of information that was important in order to facilitate the allocation of photos to verbal categories during the analysis.

In most cases, the children made lively comments on the photos portraying their family members, which often evoked detailed narrations about the persons displayed. Other issues that were elaborated on vividly were family activities. Yet the photos not only supported the children in verbalizing their thoughts but also stimulated narrations about sensitive topics, such as critical aspects of family life, 
negative views towards family members, criticisms of parental behaviour, or violent disputes among siblings (Zartler \& Richter, 2014). These are issues that usually are difficult to address in interviews with children.

At the end of the interviews, the children were asked about their motivations for participating in the study. The reasons for the children's eagerness to participate in the study were their general interest in scientific work and the content of the project, but also their enthusiasm about taking photos and explaining them to the researchers. The interviewed children appreciated their active involvement in data production and the adults' confidence in their abilities to handle the camera.

\section{Analyzing interviews}

Detailed interview protocols were prepared after conducting the interviews, containing information on the interview atmosphere, the course of conversation, specificities of the children or the photos. These protocols were essential in the process of analysis, as they also included references to the photos which made it easier to relate the relevant pictures to the children's verbal comments.

During the analysis, visual and verbal elements are closely interlaced, as it is difficult to determine what children mean without knowing the pictures they refer to. Reciprocally, it is nearly impossible to analyze photos that were taken in such a research context without making connections to the verbal parts of the interview. For example, a portrait of a family member only becomes meaningful in the analysis when researchers have knowledge about that person's relationship with and significance to the interviewed child, the reasons for portraying this person, et cetera. Nevertheless, methods of analysis usually concentrate either on verbal or on visual data.

In the present study, we continually related the photos to the verbal transcripts during the interpretation process. We returned to the pictures when analyzing the interviews on an individual level and performed a descriptive analysis of all photos and all interviews, constantly comparing and relating verbal and visual material.

As an initial step, the pictures produced by each respondent were categorized and allocated to the five main categories, according to the children's accounts. The interview text was intensively used in the course of categorization. Although the pictures could sometimes be allocated to several categories at a first glance, the interview transcripts supported the researchers in determining the category a particular photo was produced for. In the end, every photo was only coded once, in close relation to the interview text. The main criterion for categorization was children's allocation of photos to the categories during the interview, which was never overruled by the researchers' interpretations. Although most children had allocated the main part of their photos to categories, some photos remained uncategorized. These photos were then allocated by the researchers during the analysis. Thus, every single photo was categorized - a large majority by the interviewed children, and the remainder by the research team.

Secondly, sub-categories were developed, emerging from the photos in order to make the description more precise and detailed. For example, the category "Who is 
part of my family?" was divided into close relatives (mother, father, brother, sister), extended family (grandparents, uncle, aunt, cousins), and others (pets, friends, childcare persons who were considered as being part of the family). Subsequently, it was explored (a) how many children took photos of a specific (sub-)category and (b) how many photos were taken and allocated to a specific (sub-)category. The categorization was carried out by the author together with one other project team member, whenever possible relying on children's narrations and allocations. Constant comparison was used in order to check the validity of categorization.

The categorization was followed by a description of the content and the motives, relying on all photos allocated to a specific (sub-)category: What exactly did the children photograph? In which ways were the different categories presented (e.g., family members together on one photo, individual portraits of every family member, photos with mixed groups of relatives, et cetera)? Which similarities and differences could be identified? How did the children explain their motivations for producing the photos for this specific (sub-)category? Some questions, in particular the last one, could only be answered in relation to the interview text.

The analysis revealed that a major part of the photos referred to (a) children's family members and friends, (b) children's living and housing situations (their own room, their house, parks in the vicinity), and (c) activities within the family, (e.g., playing, going on excursions, pursuing hobbies, cuddling with their parents, helping in their parents' business, et cetera). Table 1 gives an overview of the percentage of pictures that were taken with regard to each category.

Table 1

Percentage of photos allocated to a category

\begin{tabular}{l|l}
\hline Category & $\%$ \\
\hline Who is part of my family? & 44 \\
\hline How we spend our time during the week. & 29 \\
\hline How we spend our time on weekends. & 15 \\
\hline What I like about my family. & 9 \\
\hline What I don't like about my family. & 3
\end{tabular}

Based on $n=992$ photos with identifiable motives

The most unpopular category was "What I don't like about my family.” Only half of the children took photographs on this issue, although we had asked them explicitly to take at least one picture for each category. Thus, the request to picture critical aspects of family life might have overburdened a considerable proportion of the participants, perhaps due to its sensitivity, as they found it difficult to capture their feelings of dislike in a visible format, or simply because they did not feel like taking such pictures. Most children who did not take any photos regarding this matter argued that they liked everything about their family. Several children who had not taken photos on this subject used others (e.g., portraits of their parents) to elaborate on critical aspects regarding family members during the interview. In general, the interviewers tried to address categories that were not represented on the photos. 


\section{Discussion: Aspects of Children's Participation During the Research Process}

As explained above, photo interviews are often regarded as a method that is particularly effective in enhancing children's participation. Based on the experiences gathered in the study presented here, I argue that it is crucial to consider this important issue throughout the entire research process and that an adequate combination of visual and verbal elements in preparing, guiding, and analyzing the interviews may facilitate children's possibilities for participation.

Photo interviews with participant-produced pictures, in particular, have the potential to support participative elements in research with children. In the study at hand, children felt acknowledged due to their active involvement in data production, and appreciated the fact that adult researchers relied on their competence to handle the cameras, to take the photos according to the specified schedule, and to act as competent narrators during the interview. This may support an empowering research experience, as the children explained the photographs taken in their own life spheres to the interviewers. They had the opportunity to make their own perspectives explicit to an adult researcher.

When using photo interviews, the ways for participation are developed at a very early stage of the research, even before approaching the respondents, which require detailed reflections within the research team. During the preparation phase, it is of importance not to exclude particular (groups of) children by designing the whole research setting as openly as possible. Nevertheless, even the most thorough consideration of research methods, respondents' characteristics, and recruitment strategies cannot overcome differences between children, (e.g., with regard to verbal abilities or their willingness to share their thoughts during an interview). Such variations were also noticeable in the study at hand: Some children talked more eloquently while others remained relatively silent, and the photos were of differing quality. In the end, the research team endeavored to treat all contributions equally. During the research process, it was evident that the "quality" of photos or interviews could not be judged at first glance. At times, for example, photos stimulated narrations on issues that were not displayed, and silence spoke louder than words (see Zartler \& Richter, 2014).

Children's active participation is also imperative when conducting the interview. While in this study, specifications were made for the production of the photos, the interviews were structured in accordance with the children's conceptions and their preferences in talking about the pictures. Rather than asking children to provide written comments on their photos, we argue in favor of integrating the participant-produced photos into a research interview and encouraging the children to comment on them in an open and storytelling way.

The consideration of children's participation during the analysis of interviews presents a particular challenge, as in most research studies their active involvement is usually not foreseen during this phase. Thus, in a setting in which researchers analyze the interview transcripts among themselves, children are excluded. Due to financial restrictions, it was not possible to integrate children directly into the analysis. Nevertheless, the children participated indirectly by discussing the data they had 
collected and categorizing their pictures. The researchers then re-coded the photos, always prioritizing the children's own interpretations.

To the best of my knowledge, settings that include children in analysis meetings are relatively rare in scientific research (for an exception, see Thomas \& O'Kane, 1998), though more often used in assessment processes on a policy level or in terms of strongly policy-related research settings (Sinclair, 2004). Attractive possibilities in order to further children's participation during this research stage would be to analyze parts of the interviews together, or to organize a discussion for feedback on the results with children who participated in the research. As such assessments ideally include several respondents, an important consideration is to guarantee anonymity in order not to expose particular individuals. Furthermore, the composition of such groups of children should be a matter of consideration.

In their work on participatory methods, Gallacher and Gallagher (2008) refer to several activities with regard to photo interviews that cannot be described as "participation”:

Children may do a range of things with cameras: take pictures of things they find interesting; take pictures of what they think the researcher wants to see; take pictures of their friends; explain to the researcher why they are taking each picture; take lots of pictures but say nothing about them, even when asked; ask the researcher to take pictures for them; give the camera to someone else; take no pictures; they may even break the camera deliberately. (p. 507)

In the study at hand, repeated contacts between researchers and children as well as the endeavor to make the use of the cameras and their significance within the study transparent, helped to minimize challenges arising from the described issues. One further aspect possibly is selection, as children who were not interested in taking photos did not participate in the study.

It is the researchers' responsibility to design the research in a way that allows for different and unexpected ways of participation, provides ample space for a range of possible settings, and does not set up norms of "appropriate” forms of participation. It seems crucial to reflect the researchers' and the children's activities and interventions, and to regard participation as a matter of course during the whole research process. Participation is not an option that should be granted to children by a generous researcher, but should represent one of the inherent principles that guide research with children.

\section{Conclusion}

Drawing on data from an Austrian empirical study with 50 10-year-old children, I explored the potential of an interview type that brings together photo interviews and semi-structured interviews based on topic guides. Several benefits were shown to be connected with this approach. For example, a thorough combination of visual and verbal elements offers children the opportunity to take part in the research process as active participants and is able to overcome some of the disadvantages that conventional "words-alone" interviews with children present. During different research stages, possibilities for participation vary and need to be 
considered adequately. One crucial issue is to combine the visual and the verbal in a way that respects children's autonomy.

Despite the considerable participative and inclusive potential of photo interviews in research with children, there are also limitations, and photo interviews are not inherently superior to any other research method. It must be considered that this method does not "solve the fundamental problem that language remains the dominant medium of communication and representation" (Warming, 2011, p. 50), thus favoring verbally inclined children (also see James, 2007). Even the most thorough combination of visual and verbal parts cannot overcome this weakness. Nevertheless, it contributes to balance both aspects and to consider photos as not merely simple supplements of verbal expression.

Summing up, although aiming at decreasing power imbalances between the researcher and the researched (Packard, 2008; Pink, 2013; Prosser \& Schwartz, 2006), the method does not per se decrease power differentials, enhance participation, or respect children's agency (Gallacher \& Gallagher, 2008; Holland et al., 2010; Punch, 2002b; Thomson, 2007). Nevertheless, photo elicitation has a significant potential to facilitate such action if applied carefully, critically, and conscientiously. 
International Journal of Child, Youth, and Family Studies (2014): 5(4.1) 629-648

\section{References}

Alderson, P. (2005). Ethics. In N. Fraser, V. Lewis, S. Ding, M. Kellett, \& C. Robinson (Eds.), Doing research with children and young people (pp. 97112). London, Thousand Oaks, New Delhi: Sage.

Backett-Milburn, K., \& McKie, L. (1999). A critical appraisal of the draw and write technique. Health Education Research, 14(3), 387-398. http://dx.doi.org/10.1093/her/14.3.387

Birney, D. P., \& Sternberg, R. J. (2011). The development of cognitive abilities. In M. H. Bornstein \& M. E. Lamb (Eds.), Developmental science. An advanced textbook (pp. 353-388). New York: Psychology Press.

Cappello, M. (2005). Photo interviews. Eliciting data through conversations with children. Field Methods, 17(2), 170-182. http://dx.doi.org/10.1177/1525822x05274553

Christensen, P., \& James, A. (Eds.). (2008). Research with children: Perspectives and practices (2nd ed.). London, New York: Falmer Press.

Clark, C. D. (1999). The autodriven interview: A photographic viewfinder into children’s experiences. Visual Sociology, 14(1), 39-50. http://dx.doi.org/10.1080/14725869908583801

Clark-Ibáñez, M. (2004). Framing the social world through photo-elicitation interviews. American Behavioral Scientist, 47(12), 1507-1527.

Clark-Ibáñez, M. (2007). Inner-city children in sharper focus: Sociology of childhood and photo-elicitation interviews. In G. Stanczak (Ed.), Visual research methods: Image, society, and representation (pp. 167-196). London: Sage Publications.

Collier, J. (1967). Visual anthropology. Photography as a research method. Newbury Park, CA: Holt, Rinehart and Winston.

Cook, T., \& Hess, E. (2007). What the camera sees and from whose perspective. Fun methodologies for engaging children in enlightening adults. Childhood, 14(1), 29-45. http://dx.doi.org/10.1177/0907568207068562

Cooper, A., Nazzari, V., Kon Kam King, J., \& Pettigrew, A. (2013). Speaking rights: Youth empowerment through a participatory approach. International Journal of Child, Youth and Family Studies, 4(3.1), 489-501.

Croghan, R., Griffin, C., Hunter, J., \& Phoenix, A. (2008). Young people's constructions of self: Notes on the use and analysis of the photo-elicitation methods. International Journal of Social Research Methodology, 11(4), 345356. http://dx.doi.org/10.1080/13645570701605707

Darbyshire, P., MacDougall, C., \& Schiller, W. (2005). Multiple methods in qualitative research with children: more insight or just more? Qualitative Research, 5(4), 417-436. http://dx.doi.org/10.1177/1468794105056921 
International Journal of Child, Youth, and Family Studies (2014): 5(4.1) 629-648

Denham, S., Warren, H., Salisch, M. v., Benga, O., Chin, J.-C., \& Geangu, E. (2011). Emotions and social development in childhood. In P. K. Smith \& C. H. Hart (Eds.), The Wiley-Blackwell handbook of childhood social development (2nd ed., pp. 413-433). Chichester, UK: Wiley-Blackwell.

Eder, D., \& Fingerson, L. (2001). Interviewing children and adolescents. In J. F. Gubrium \& J. A. Holstein (Eds.), Handbook of interview research (pp. 181202). Thousand Oaks, London, New Delhi: Sage. http://dx.doi.org/10.4135/9781412973588.d13

Einarsdóttir, J. (2005). Playschool in pictures: Children’s photographs as a research method. Early Child Development and Care, 175(6), 523-541. http://dx.doi.org/10.1080/03004430500131320

Eldén, S. (2012). Inviting the messy: Drawing methods and 'children’s voices'. Childhood, 20(1), 66-81. doi: 10.1177/0907568212447243

Flick, U. (2014). An introduction to qualitative research: Theory, method and applications (5th ed.). London: Sage.

Fraser, S., Lewis, V., Kellett, M., \& Robinson, C. (Eds.). (2004). Doing research with children and young people. London: Sage.

Froschauer, U., \& Lueger, M. (2003). Das qualitative interview. [The qualitative interview]. Vienna: WUV.

Fuhs, B. (2000). Qualitative interviews mit kindern. Überlegungen zu einer schwierigen methode. [Qualitative interviews with children. Considerations regarding a difficult method]. In F. Heinzel (Ed.), Methoden der kindheitsforschung. Ein Überblick über Forschungszugänge zur kindlichen Perspektive. [Methods of childhood research. An overview on research approaches considering children's perspectives] (pp. 87-104). Weinheim and Munich: Juventa.

Gallacher, L.-A., \& Gallagher, M. (2008). Methodological immaturity in childhood research? Childhood, 15(4), 499-516. doi: 10.1177/0907568208091672

Graham, A., \& Fitzgerald, R. (2010). Progressing children's participation: Exploring the potential of a dialogical turn. Childhood, 17(3), 343-359. doi:

$10.1177 / 0907568210369219$

Greig, A., Taylor, J., \& MacKay, T. (Eds.). (2007). Doing research with children. Los Angeles: Sage.

Harper, D. (2001). Changing works: Vision of lost agricultures. Chicago: University of Chicago Press.

Harper, D. (2002). Talking about pictures: A case for photo elicitation. Visual Studies, 17(1), 13-26.

Heinzel, F. (Ed.). (2000). Methoden der Kindheitsforschung. Ein Überblick über Forschungszugänge zur kindlichen Perspektive. [Methods of childhood 
International Journal of Child, Youth, and Family Studies (2014): 5(4.1) 629-648

research. An overview on research approaches considering children's perspectives]. Weinheim and Munich: Juventa.

Hill, M. (1997). Participatory research with children. Child and Family Social Work, 2(3), 171-183.

Hill, M. (2006). Children's voices on ways of having a voice: Children's and young people's perspectives on methods used in research and consultation. Childhood, 13(1), 69-89. doi: 10.1177/0907568206059972

Hill, M., Davis, J., Prout, A., \& Tisdall, K. (2004). Moving the participation agenda forward. Children \& Society, 18(2), 77-96. doi: 10.1002/CHI.819

Holland, P. (1997). Sweet it is to scan: Personal photographs and popular photography. In L. Wells (Ed.), Photography: A critical introduction (pp. 105-132). London: Routledge.

Holland, S., Renold, E., Ross, N. J., \& Hillman, A. (2010). Power, agency and participatory agendas: A critical exploration of young people's engagement in participative qualitative research. Childhood, 17(3), 360-375. doi: $10.1177 / 0907568210369310$

James, A. (2007). Giving voice to children's voices: Practices and problems, pitfalls and potentials. American Anthropologist, 109(2), 261-272. doi: 10.1525/aa.2007.109.2.261

James, A. (2009). Agency. In J. Qvortrup, W. A. Corsaro, \& M.-S. Honig (Eds.), The Palgrave handbook of childhood studies (pp. 34-45). Houndmills, Basingstoke, UK: Palgrave Macmillan.

James, A., Jenks, C., \& Prout, A. (1998). Theorizing childhood (2nd ed.). Cambridge: Polity Press.

Jorgenson, J., \& Sullivan, T. (2009). Accessing children's perspectives through participatory photo interviews. Forum Qualitative Social Research, 11(1), http://nbn-resolving.de/urn:nbn:de:0114-fqs100189.

Kolb, B. (2008). Involving, sharing, analysing - Potential of the participative photo interview. Forum Qualitative Social Research, 9(3), http://nbnresolving.de/urn:nbn:de:0114-fqs0803127.

Kuczynski, L. (2003). Beyond bidirectionality. Bilateral conceptual frameworks for understanding dynamics in parent-child relations. In L. Kuczynski (Ed.), Handbook of dynamics in parent-child relations (pp. 3-24). Thousand Oaks, CA: Sage. http://dx.doi.org/10.4135/9781452229645.n1

Lamnek, S. (1995). Qualitative sozialforschung. [Qualitative social research]. Weinheim, Beltz: Psychologie Verlags Union. 
International Journal of Child, Youth, and Family Studies (2014): 5(4.1) 629-648

Lange, A., \& Mierendorff, J. (2009). Method and methodology in childhood research. In J. Qvortrup, W. A. Corsaro, \& M.-S. Honig (Eds.), The Palgrave handbook of childhood studies (pp. 78-95). Houndmills, Basingstoke, UK: Palgrave Macmillan.

Lewis, R. (2009). Recruiting parents and children into a research project: A qualitative exploration of families' decision-making processes. International Journal of Social Research Methodology, 12(5), 405-419. http://dx.doi.org/10.1080/13645570802289104

Mannay, D. (2010). Making the familiar strange: Can visual research methods render the familiar setting more perceptible? Qualitative Research, 10(1), 91-111. http://dx.doi.org/10.1177/1468794109348684

Mason, J., \& Tipper, B. (2008). Being related: How children define and create kinship. Childhood, 15(4), 441-460. doi: 10.1177/0907568208097201

McBrien, J. L., \& Day, R. (2012). From here to there: Using photography to explore perspectives of resettled refugee youth. International Journal of Child, Youth and Family Studies, 3(4.1), 546-568.

Morris, J. (2003). Including all children: Finding out about the experiences of children with communication and/or cognitive impairments. Children \& Society, 17(5), 337-348. doi: 10.1002/CHI.754

Morrow, V. (1998). Understanding families: Children's perspectives. London: Rowntree.

Morrow, V. (2003). Perspectives on children's agency within families. A view from the sociology of childhood. In L. Kuczynski (Ed.), Handbook of dynamics in parent-child relations (pp. 109-129). Thousand Oaks, CA: Sage. http://dx.do.org/10.4135/9781452229645.n6

Neale, B. (2002). Dialogues with children: Children, divorce and citizenship. Childhood, 9(4), 455-475. doi: 10.1177/0907568202009004006

Newman, M., Woodcock, A., \& Dunham, P. (2006). Playtime in the borderlands: Children's representations of school, gender and bullying through photographs and interviews. Children's Geographies, 4(3), 289-302. http://dx.doi.org/10.1080/14733280601005617

Packard, J. (2008). 'I'm gonna show you what it's really like out here': The power and limitation of participatory visual methods. Visual Studies, 23(1), 63-77. doi: 10.1080/14725860801908544

Piaget, J. (1972). The psychology of the child. New York: Basic Books.

Pink, S. (2013). Doing visual ethnography. London: Sage.

Powell, M. A., \& Smith, A. B. (2009). Children’s participation rights in research. Childhood, 16(1), 124-142. doi: 10.1177/0907568208101694 
International Journal of Child, Youth, and Family Studies (2014): 5(4.1) 629-648

Prosser, J., \& Schwartz, D. (2006). Photographs within the sociological research process. In P. Hamilton (Ed.), Visual research methods (pp. 115-128). London: Sage.

Punch, S. (2002a). Interviewing strategies with young people: The 'secret box', stimulus material and task-based activities. Children \& Society, 16(1), 45-56. doi: 10.1002/chi.685

Punch, S. (2002b). Research with children: The same or different from research with adults? Childhood, 9(3), 321-341. http://dx.doi.org/10.1177/0907568202009003005

Qvortrup, J., Corsaro, W. A., \& Honig, M.-S. (2009). The Palgrave handbook of childhood studies. Houndmills, Basingstoke, UK: Palgrave Macmillan.

Rabiee, P., Sloper, P., \& Beresford, B. (2005). Doing research with children and young people who do not use speech for communication. Children \& Society, 19(5), 385-396. doi: 10.1002/chi.841

Ribbens McCarthy, J., Holland, J., \& Gillies, V. (2003). Multiple perspectives on the 'family' lives of young people: Methodological and theoretical issues in case study research. International Journal of Social Research Methodology, 6(1), 1-23. http://dx.doi.org/10.1080/13645570305052

Rigg, A., \& Pryor, J. (2007). Children's perceptions of families: What do they really think? Children \& Society, 21, 17-23. doi: 10.1111/j.1099-0860.2006.00028.x

Roberts, H. (2008). Listening to children: and hearing them. In P. Christensen \& A. James (Eds.), Research with children: Perspectives and practices (2nd ed., pp. 260-275). London, New York: Falmer Press.

Schwartz, D. (1989). Visual ethnography: Using photography in qualitative research. Qualitative Sociology, 12(2), 119-153. http://dx.doi.org/10.1007/bf00988995

Schwartz, D. (1992). Wacoma twilight: Generations on the farm. Washington, DC: Smithsonian Press.

Shehan, C. L. (Ed.). (1999). Contemporary perspectives on family research. Through the eyes of the child. Revisioning children as active agents of family life. Stamford, CT: JAI Press.

Sinclair, R. (2004). Participation in practice: Making it meaningful, effective and sustainable. Children \& Society, 18(2), 106-118. doi: 10.1002/chi.817

Smart, C. (2006). Children's narratives of post-divorce family life: From individual experience to an ethical disposition. The Sociological Review, 54(1), 155-170. doi: 10.1111/j.1467-954X.2006.00606.x

Strauss, A., \& Corbin, J. (1990). Basics of qualitative research: Grounded theory procedures and techniques. Newbury Park, CA: Sage. 
International Journal of Child, Youth, and Family Studies (2014): 5(4.1) 629-648

Thomas, N., \& O'Kane, C. (1998). The ethics of participatory research with children. Children \& Society, 12(5), 336-348. doi: 10.1111/j.1099-0860.1998.tb00090.x

Thomson, F. (2007). Are methodologies for children keeping them in their place? Children's Geographies, 5(3), 207-218. doi: 10.1080/14733280701445762

Thomson, P. (Ed.). (2008). Doing visual research with children and young people. London, New York: Routledge.

Valentine, K. (2011). Accounting for agency. Children \& Society, 25(5), 347-358. doi: 10.1111/j.1099-0860.2009.00279.x

Wang, C., \& Burris, M. A. (1997). Photovoice: Concept, methodology and use for participatory needs assessment. Health Education Behaviour, 24(3), 369-387. http://dx.doi.org/10.1177/109019819702400309

Wang, C., Ling, Y. Y., \& Ling, F. M. (1996). Photovoice as a tool for participatory evaluation: The community's view of process and impact. The Journal of Contemporary Health, 4, 47-49.

Warming, H. (2011). Getting under their skins? Accessing young children's perspectives through ethnographic fieldwork. Childhood, 18(1), 39-53. doi: $10.1177 / 0907568210364666$

White, A., Bushin, N., Carpena-Méndez, F., \& Ní Laoire, C. (2010). Using visual methodologies to explore contemporary Irish childhoods. Qualitative Research, 10(2), 143-158. http://dx.doi.org/10.1177/1468794109356735

Worth, S., \& Adair, J. (1972). Through Navajo eyes: An exploration in film communication and anthropology. Bloomington: Indiana University Press.

Wuggenig, U. (1990). Die Fotobefragung als projektives Verfahren. [Photo interviews as a projective method]. Angewandte Sozialforschung, 16(1/2), 109-129.

Zartler, U. (2010). Multiple perspectives in qualitative family research: Crafting and conducting research projects. Family Science, 1 (3-4), 173-182. doi: 10.1080/19424620.2010.569371

Zartler, U. (2014). How to deal with moral tales: Constructions and strategies of single-parent families. Journal of Marriage and Family, 76(3), 604-619. doi: 10.1111/jomf.12116

Zartler, U., \& Richter, R. (2014). My family throuth the lens. Photo interviews with children and sensitive aspects of family life. Children \& Society, 28 (1), 4254. doi: 10.1111/j.1099-0860.2012.00447.x

Ziller, R. (1990). Photographing the self: Methods for observing personal orientations. Newbury Park, CA: Sage. 